\title{
122 ステレオPIVによる円柱後流の三次元渦度計測
}

吉田 雅之（筑波大学大学院）、榊原 潤（筑波大学機能工）

\section{Stereo-PIV study of 3D vortical structures in a cylinder wake}

\author{
Masayuki YOSHIDA and Jun SAKAKIBARA
}

\begin{abstract}
Measurements of velocity/vorticity of cylinder wake by using stereo-PIV method.Three-dimensional vorticity iso-surfaces were successfully reconstructed from temporal series of velocity in a crosssectional plane assuming Taylor's hypothesis. Vortex structure having a mode A pattern was observed at $\mathrm{Re}=1000$.
\end{abstract}

Keyword PIV, vortical structure, cylinder wake

\section{1. 緒言}

物体の周囲を流体が流れる系は多くの工業的分野 に見られる。特に物体が円柱の場合には、いわゆる力 ルマン渦構造を伴う円柱後流が存在し、円柱に非定 常的な振動が加わることが知られている。円柱後流 は 2 つの二次元的なせん断層を有する流れであり、 その初期流れの微小变化は $\mathrm{K}-\mathrm{H}$ 不安定及び二次的不 安定性により増幅され、せん断渦およびリブ構造が 成長していくことが染料による可視化ならびに、数 值計算により明らかとなっている(1)。一方、実験結果 に基づいた渦度場の可視化は計測法の困難さに起因 して行われていない。そこで、本研究ではステレオ PIVを用いた実験的計測手法により円柱後流の主流方 向に垂直な断面おける速度 3 成分を時系列に計測し， 渦度分布を三次元的に可視化することを目的とする。

\section{2. 実験装置及び実験方法}

実験装置の概略をFig.1に示す。トレーサー粒子(ダ イアミド、粒子径約 $40 \mu \mathrm{m}$ ）を懸濁したアクリル製水 槽(長さ $1000 \mathrm{~mm} \times$ 奥行き $200 \mathrm{~mm} \times$ 深さ $300 \mathrm{~mm}$ )内で、 直径 $\mathrm{D}=20 \mathrm{~mm}$ アスペクト比 8.0 の円柱を水槽上部に取 り付けられた電動送り装置（ロボシリンダ、IAI）に より一定速度Uで移動し、鉛直に照射したレーザー シートによって流動場を可視化した。

水槽内の水が静止した後円柱を移動させ、円柱が レーザーシートを通過した直後のレーザーシート面 の画像をCCDカメラ0,1 (kodak, ESI, 0) を用いてPC に取り込んだ。得られた画像からステレオPIV法(2)を 用いて瞬時の速度3成分を得て、さらに得られた時系

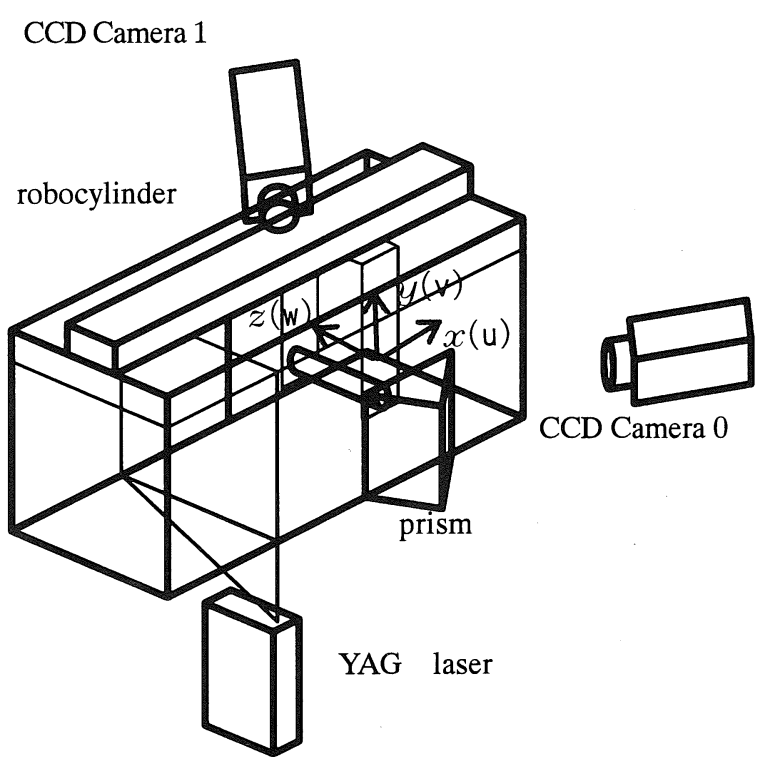

Fig.1 Experimental apparatus

列速度デー夕の時間方向をテーラーの凍結仮説に基 づいて流れ方向に置き換えることで、流れの速度勾 配を求め、渦度 3 成分の三次元分布を得た。ここで渦 の移流速度を $U / 2$ と仮定し流れ方向距離を $x^{*}=-t U / 2$ とおく。これを用いて次式のように 定義された渦度を、得られた速度データから算出し た。

$$
\begin{aligned}
& \omega_{x}=\frac{\partial w}{\partial y}-\frac{\partial v}{\partial z}, \quad \omega_{y}=\frac{\partial u}{\partial z}-\frac{\partial w}{\partial t} \frac{\partial t}{\partial x} \\
& \omega_{z}=\frac{\partial v}{\partial t} \frac{\partial t}{\partial x}-\frac{\partial u}{\partial y}
\end{aligned}
$$

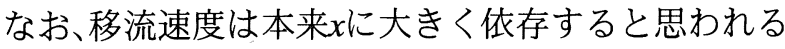
が、その実測值がなかったため、ここでは上記のよう に定数とした。 


\section{3. 実験結果及び考察}

$D$ に基づいたレイノルズ数 $R e_{\mathrm{D}}=1000(U=55 \mathrm{~mm} / \mathrm{s})$ で の円柱後流三次元渦度分布を Fig.2に示す。せん断渦 の主要な渦度成分として、 $\left|\omega_{z}\right| \cdot D / U=1.4$ の等值面を 黒で、またリブ構造として $\left|\omega_{x}\right|\left(\omega_{x}^{2}+\omega_{y}^{2}\right)^{1 / 2} \cdot D / U$ $=1.4$ の等值面を白で、 $\left|\omega_{x}\right|\left(\omega_{x}^{2}+\omega_{y}^{2}\right)^{1 / 2} \cdot D / U=-1.4$ の等値面を縞模様で示している。Fig.2(a)、(b)、(c)は、 同じ結果をそれぞれ異なる角度から見たものである。 図中、主流方向は右向きで $t=0$ に円柱の背面が位置す る。Fig.2(c)より円柱背面では $y / D=0.5 、 y / D=-0.5$ にせ ん断層が存在し、その後方にロールアップしたせん 断渦、A、Bが確認される。この 2 つのせん断渦の間 から縦渦Dが下流に伸び、また、Bの下流側から縱渦 Cが伸びていることが分かる。Fig.2(a)、(b)において 上側せん断層の縦渦は 2 対確認され、それらの間隔 は2D程度である。一方、下側せん断層には $1 \mathrm{D}$ 程度の 間隔をなした渦対構造が観察された。なお、渦の移流 速度を定数としたため、下流に行くに従って渦構造 が全体的に伸びた形となった。

Williamson(1)によれば、円柱後流の渦構造には2つ のモードがあることが知られている。縦渦の渦度 $\omega_{x}$ 成分が下流に行くに従い正、負と交互に変わるモ一 ド Aが $\mathrm{Re}<$ 約 260 で、同じ符号が続くモード B が $\mathrm{Re}>$ 約 260 において存在する。さらに、モード A はスパ ン方向波長が4D程度で最も不安定であるのに対し、 モードBでは $1 \mathrm{D}$ 程度が最も擾乱が増幅される。

本実験のレイノルズ数 $(\mathrm{Re}=1000)$ においてはモード Bの存在が期待されるが、上述の結果に見られるスパ ン方向波長(1D〜2D)はおよそ Williamson ${ }^{(1)}$ のモード Bのそれに一致するものである。しかしながら、レイ ノルズ数が $\mathrm{Re}=1000$ と比較的高く渦構造が複雑であ り、縦渦の渦度 $\omega_{x}$ 成分の正負に基づいたモードの判 断は困難である。

\section{4.まとめ}

ステレオPIVにより円柱後流の速度三成分計測を行 い、テーラーの凍結仮説に基づいて三次元渦構造の 視化をおこなった。Re=1000において、せん断渦の放 出およびせん断渦間に発生した縦渦が捉えられた。 なお、本報では渦の移流速度を定数としたため、下流 に行くに従って渦構造が伸びた形となった。今後、よ
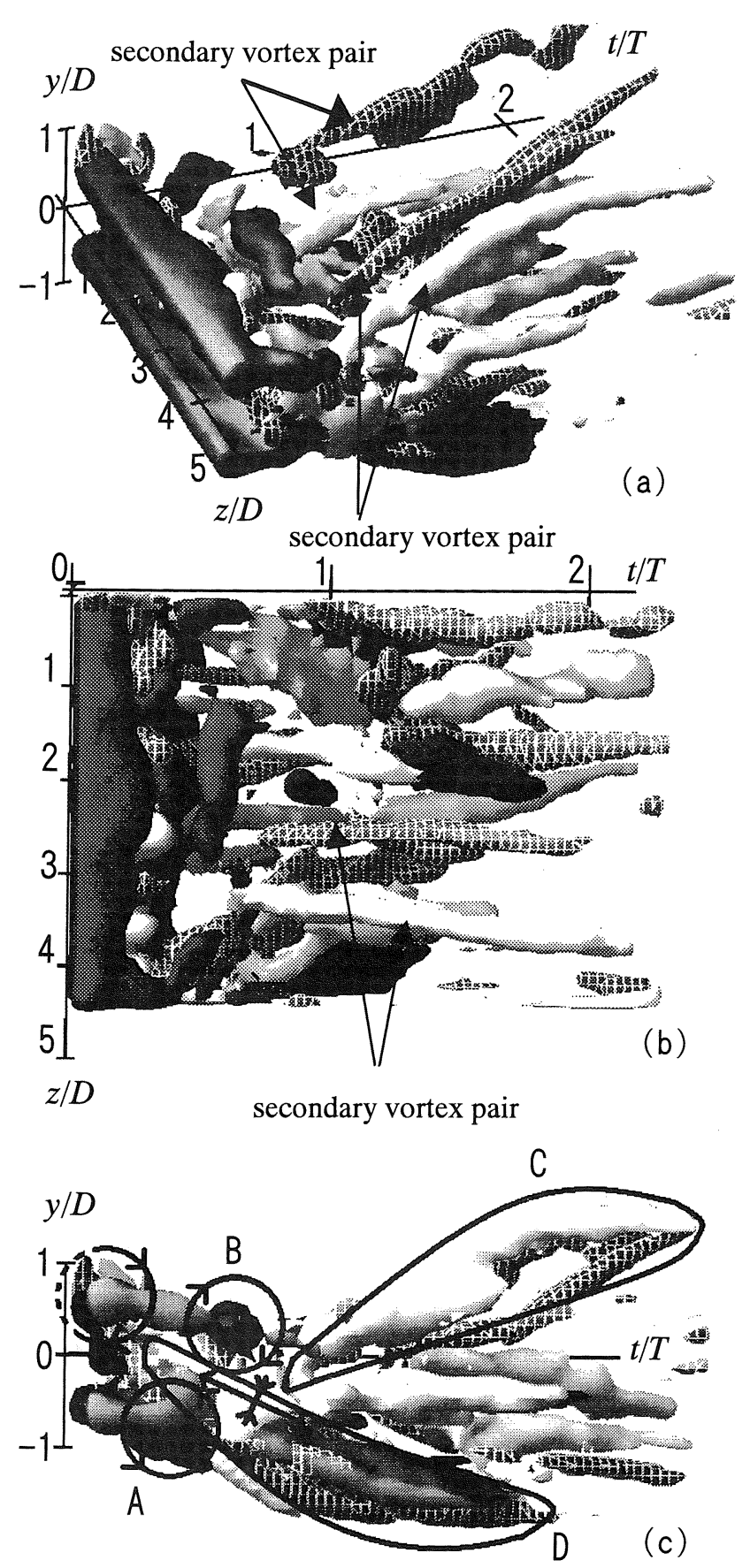

Fig.2 Iso-surface of spanwise vorticity $\omega_{z}$ and streamwise vorticity $\omega_{x}$

り適切な移流速度を用いることが課題である。

参考文献

1)Williamson.C.H.K Vortex Dynamics in the

Cylinder Wake, Annu.Rev.Fluid.Mech. ,pp.477(1996)

2)A.K.Prasad, R.J.Adrian, Stereoscopic particle image velocimetry applied to liquid flows, Exp. Fluids, 15, pp.49 (1993) 